\title{
Pelatihan Peningkatan Kompetensi Bidang Sistem Kendali Menggunakan Modul Arduino Di SMK Pangeran Antasari Balikpapan
}

\author{
Fathur Zaini Rachman ${ }^{1}$, Suhaedi ${ }^{2}$, Hadiyanto ${ }^{3}$, Ihsan ${ }^{4}$ \\ Jurusan Teknik Elektro Politeknik Negeri Balikpapan \\ Email: 1fathur.zaini@poltekba.ac.id, ${ }^{2}$ suhaedi@poltekba.ac.id, \\ 3hadiyanto@poltekba.ac.id, 4ihsan@poltekba.ac.id
}

\begin{abstract}
The activity at the "Pangeran Antasari Balikpapan" Vocational School has several objectives: improving teacher competency by training and testing directly on Arduino-based practice modules that have multi-input and multi-output peripherals that have extensive functions for applications in automatic control systems. Analysis and discussion to partners there are 2 main problems, the problem of automation technology and teacher competence. The problem of automation technology is solved by training practice modules that are useful as learning media in the field of automatic control systems and can be implemented for various applications. The problem of teacher competence with technology updates is solved by the development of learning media so that the teacher is able to create and innovate in the control system. The method used in this activity is discussion, explanation, demonstration, practice, and observation..
\end{abstract}

Keyword: Vocational School, Arduino-based, teacher competency, automation technology

\section{Pendahuluan}

Sekolah Menengah Kejuruan (SMK) merupakan wadah untuk menuntut ilmu berupa pengetahuan, keterampilan dan kepribadian. Fungsi dan peran sekolah sangat penting untuk menghasilkan lulusan yang siap berkompetisi dipasar kerja dalam level middle skill. Berlatar belakang dari tujuan pendidikan seperti yang diamanahkan undang-undang yaitu Undang-Undang No. 20 Tahun 2003 tentang Sistem Pendidikan Nasional. 1 Undang-undang menyatakan bahwa penyelenggaraan pendidikan wajib memegang beberapa

1 Undang-Undang No.20 Tahun 2003 Tentang Sistem Pendidikan Nasional 
prinsip, yakni pendidikan diselenggarakan secara demokratis dan berkeadilan serta tidak diskriminatif dengan menjunjung tinggi hak asasi manusia, nilai keagamaan, nilai kultural, dan kemajemukan bangsa dengan satu kesatuan yang sistemik dengan sistem terbuka dan multimakna.

Kurikulum Sekolah Menengah Kejuruan berisi kumpulan mata pelajaran yang masing-masing mata pelajaran tersebut memiliki tujuan pembelajaran untuk mencapai kompetensi keahlian yang dipersyaratkan. Salah satu mata pelajaran pada kurikulum jurusan teknik elektronika dan komputer. Sistem operasi atau operating system adalah sebuah program yang ditujukan untuk melakukan pengaturan terhadap sumber daya yang ada dan program aplikasi lain yang dibuat. Namun biasanya sistem operasi dibuat untuk komputer dengan spesifikasi yang tinggi (PC, Mainframe). Saat ini banyak perangkat elektronik yang dibuat dengan menggunakan Mikrokontroler. Mikrokontroler merupakan salah satu dari alat pengendali yang digunakan untuk pengendalian otomatis. ${ }^{2}$ Mikrokontroler memiliki aplikasi yang luas, untuk berbagai keperluan. Modul mikrokontroler yang dirancang untuk sarana praktik siswa-siswi adalah mikrokontroller tipe yang berbasis arduino. Arduino merupakan mikrokontroller dengan port input dan output yang diprogram oleh bahasa pemrograman C. Pemilihan mikrokontroller arduino ini adalah mudah digunakan untuk berbagai aplikasi, sangat membantu bagi siswa-siswi yang baru mengenal dan belajar tentang mikrokontroller. Fungsi library (code program siap dipakai), sehingga untuk mengakses hardware sangat banyak. hardware tersebut seperti bluetooth, berbagai macam sensor, GSM board, GPS dan lainnya.

Jurusan yang ada di Sekolah Menengah Kejuruan Pangeran Antasari Balikpapan hanya terdapat Teknik Komputer Jaringan dan banyak yang

2 Qory Hidayati, Fathur Zaini Rachman, Nur Yanti, Nurwahidah Jamal, Suhaedi "Desain Model dan Simulasi PLC-Mikrokontroler sebagai Modul Pembelajaran Berbasis PLC", JTERA- Jurnal Teknologi Rekayasa, Vol. 2, No. 2, Desember 2017, Hal. 73-82 
belum mengenal atau mengetahui tentang Arduino sehingga tim jurusan teknik elektro Politeknik Negeri Balikpapan melakukan pelatihan mengenai mikrokontroler arduino dan contoh modul mikrokontroller serta menampilkan pengampilkasian secara sehingga guru dan siswa akan lebih mudah dalam mempelajari pemrograman mikrokontroller serta aplikasinya.

Berdasarkan analisis situasi di SMK Pangeran Antasari Balikpapan masih mengalami berbagai permasalahan diantanya:

1. Permasalahan terkait mikrokontroller sebagai media praktik:

a. Mikrokontroller sebagai ilmu yang baru.

b. Ketidaktahuan atas arduino itu sendiri.

2. Permasalahan kompetensi guru:

a. Kompetensi guru dalam sistem kendali berbasis arduino.

b. Jumlah guru yang menguasai mikrokontroller masih terbatas.

Melihat permasalahan yang dihadapi mitra, maka perlu prioritas terhadap permasalahan yang akan diatasi melalui kegiatan pengabdian kepada masyarakat ini. Berdasarkan analisis kebutuhan yang telah dilakukan dengan berdiskusi dengan mitra dan mempertimbangkan kemampuan tim pelaksana Ipteks, maka permasalahan yang diprioritaskan untuk diatasi melalui kegiatan ini diantaranya adalah Penjelasan mengenai mikrokontroller itu sendiri, serta memberikan beberapa contoh yang mudah dipahami, dan peningkatan kompetensi Guru-guru pengajar khususnya pada mata pelajaran mikrokontroller serta Guru-guru yang lain dalam jurusan komputer jaringan SMK Pangeran Antasari Balikpapan.

\section{Metode}

Kegiatan ini dilaksanakan dengan menggunakan pendekatan metode diskusi, ceramah, demonstrasi, praktik langsung, dan observasi seperti pada Gambar 1. 


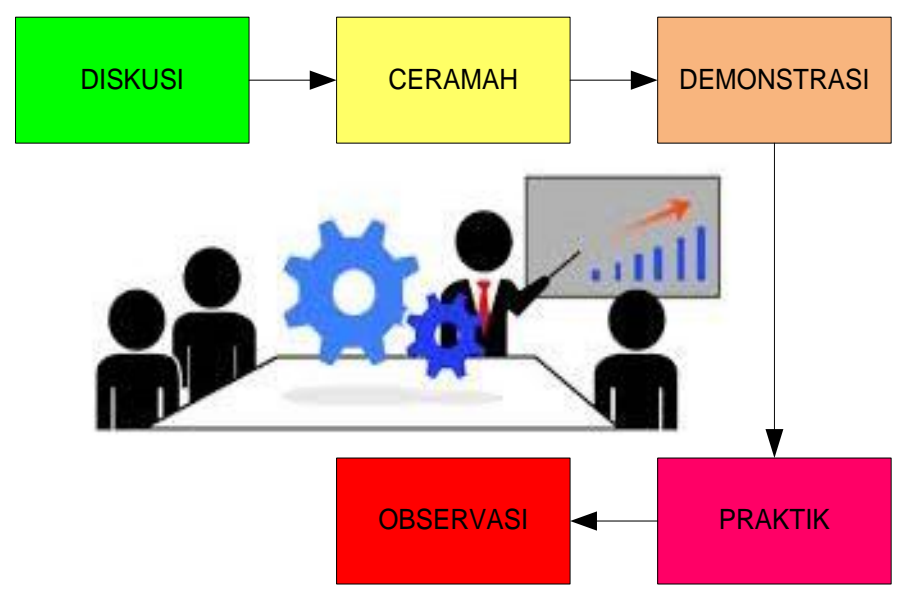

Gambar 1. Pendekatan Metode Kegiatan PkM

(Sumber: Dokumentasi, 2019)

Langkah 1: Metode diskusi Digunakan sebagai media komunikasi saat peninjauan kondisi lapangan akan ketersediaan modul praktik mikrokontroller dan materi pembelajaran tentang mikrokontroller.

Langkah 2 : Metode ceramah Digunakan dalam proses penyampaian materi pelatihan. Disamping itu digunakan juga dalam memberikan pengarahan kepada mitra untuk meningkatkan penggunaan modul mikrokontroller.

Langkah 3 : Metode demonstrasi Digunakan dalam proses memberikan contoh dalam setiap pelatihan, sehingga memberikan kemudahan kepada mitra dalam memahami materi yang disampaikan.

Langkah 4: Metode praktik Digunakan untuk mengaplikasikan modul mikrokontroller arduino kepada mitra.

Langkah 5: Metode Observasi digunakan untuk mengawasi dan mencatat kegiatan PkM dengan sengaja, sistematis dan selektif guna mendapatkan hasil dan kesimpulan dari kegiatan. 


\section{Hasil dan Diskusi}

Pada kegiatan Pengabdian Kepada Masyarakat (PKM) ini dirancang modul sistem pengendalian dengan multi input-multi output yang dapat digunakan sebagai alat praktik di SMK Pangeran Antasari Balikpapan. Modul ini dirancang beserta program aplikasi dengan menggunakan bahasa $\mathrm{C}$ sebagai bahasa pemrograman pada pengendali utama mikrokontroller Arduino. Selain itu, dalam meningkatkan kompetensi Guru dilakukan pelatihan secara intensif.

Modul Praktik Arduino yang dirancang dapat dilihat seperti pada Gambar 2.

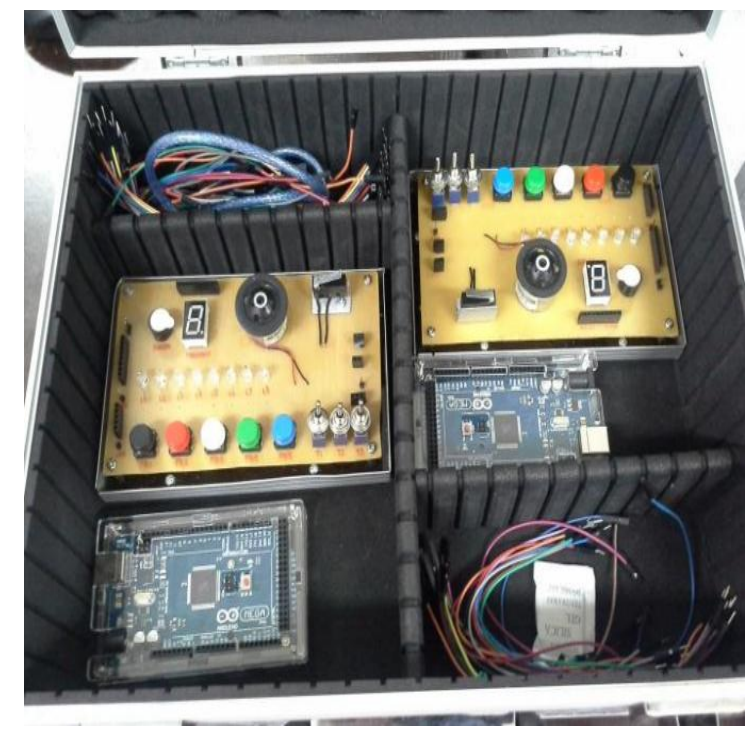

Gambar 2. Modul Praktik Arduino

(Sumber: Dokumentasi, 2019)

Modul praktik arduino dirancang dengan mengutamakan implementasi seperti pada Gambar 2. Dimana, perangkat input dan output adalah bentuk nyata dan dapat diterapkan dalam praktik dengan mudah. 
Untuk menyelesaikan permasalahan akan kompetensi guru SMK, tim melakukan pelatihan penggunaan modul praktik arduino ${ }^{3}$, seperti pada Gambar 3. Sosialisasi modul praktik seperti gambar 4, disampaikan kepada siswa SMK oleh Mahasiswa Politeknik agar dapat dimanfaatkan maksimal.
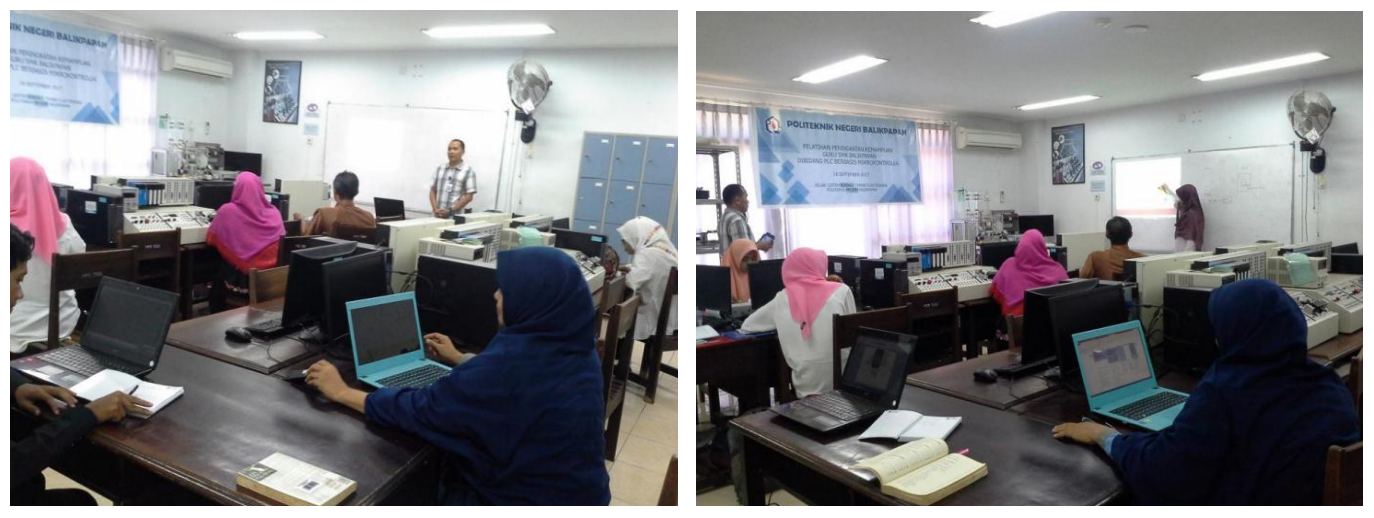

Gambar 3. Proses Penyampaian Materi dan Praktik Modul Secara Langsung Kepada Guru SMK (Sumber: Dokumentasi, 2019)

Adapun hasil pengujian dari modul praktik arduino dapat dilihat seperti pada

Tabel 1. Dimana terdapat beberapa input dan output.

Tabel 1. Hasil Input Output Modul Arduino

\begin{tabular}{|c|c|c|c|c|c|}
\hline No & Komponen & \multicolumn{2}{|c|}{ Kondisi } & $\begin{array}{c}\text { Alamat } \\
\text { Pin I/O }\end{array}$ & Keterangan \\
\hline 1 & Toggle Switch & On & Off & 23 & Input \\
\hline 2 & Push Button & On & Off & 24 & Input \\
\hline 3 & Limit Switch & On & Off & 25 & Input \\
\hline 4 & Motor DC & Putar & Mati & 13 & Output \\
\hline 5 & Buzzer & Bunyi & Mati & 12 & Output \\
\hline 6 & LED & Nyata & Mati & $2-9$ & Output \\
\hline
\end{tabular}

Sumber: Dokumentasi, 2019

\footnotetext{
3 Fathur Zaini Rachman, " Mikroprosesor dan Teknik Antar Muka”, Buku Ajar Politeknik Negeri Balikpapan, 2018
} 
Seperti pada Gambar 4, penyampaian dan diskusi akan masalah yang sering dihadapi dalam penggunaan modul praktik arduino oleh guru. Dalam proses ini dilakukan uji coba secara langsung modul dan mempraktikkan pada komputer masing-masing orang agar materi dapat tersampaikan.
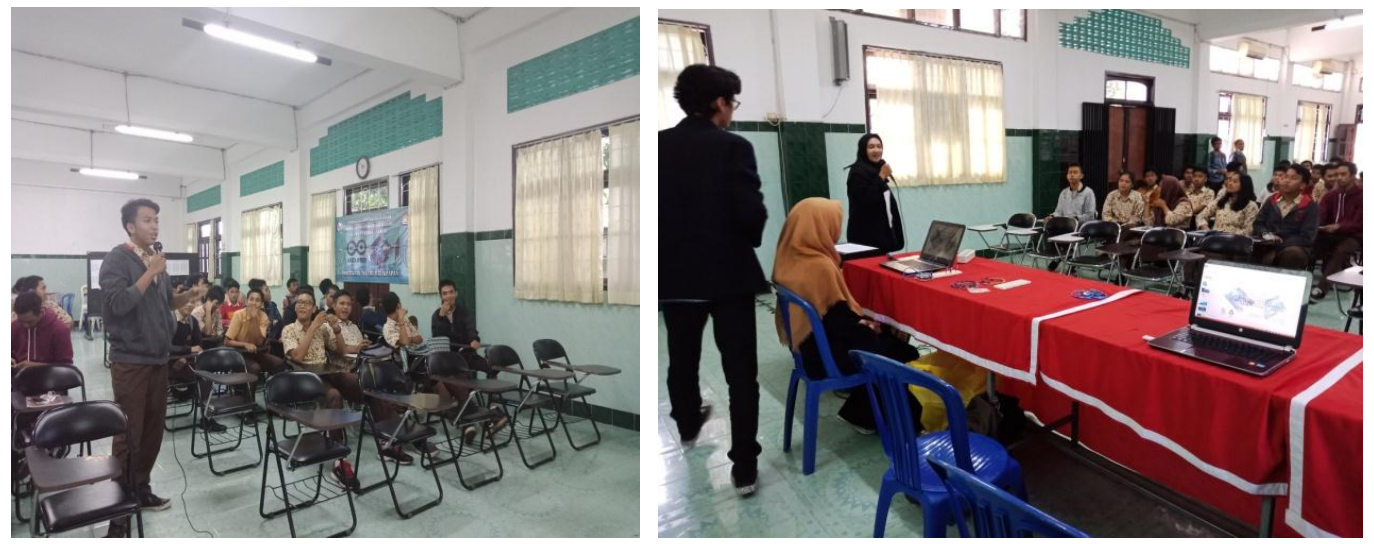

Gambar 4. Sosialisasi Modul Praktik Arduino Kepada Siswa SMK oleh Mahasiswa Politeknik Negeri Balikpapan (Sumber: Dokumentasi, 2019)

Sosialisasi dilakukan kepada siswa SMK agar dapat menggunakan modul praktik bersama guru pada saat pelaksanaan pratikum sistem kendali. penyampaian dan diskusi dalam penggunaan modul praktik arduino oleh mahasiswa. Dalam kegiatan ini, siswa diinformasikan akan tersedianya modul praktik yang akan mereka gunakan setelah pelaksanaan PkM. Sehingga mahasiswa dapat memaksimalkan modul tersebut secara bersama.

\section{Simpulan}

Hasil dari proses kegiatan Pengabdian kepada Masyarakat (PkM) yang dilakukan menghasilkan suatu kesan positif bagi para guru dan siswa di SMK Pangeran Antasari Balikpapan. Sebagai contoh para siswa dan guru yang hadir dalam pelatihan sangat antusias dalam menyimak materi dan demonstrasi yang kami selaku tim PKM penyelengara. Beberapa siswa yang sebelumnya sudah pernah mengikuti lomba kreatifitas teknologi sangat aktif

Pelatihan Peningkatan Kompetensi Bidang Sistem Kendali Menggunakan Modul Arduino Di SMK Pangeran Antasari Balikpapan

Fathur Zaini Rachman, Suhaedi, Hadiyanto, Ihsan 
dalam menanyakan system kerja dan permasalahan yang sering terjadi pada Arduino. Sehingga mereka yang belum mengenal Arduino dapat mengerti dan dapat mengaplikasikan di kemudian hari.

Berdasarkan kesimpulan dapat diberikan saran yang berkenaan dengan pengembangan dan penyempurnaan modul untuk pengabdian masyarakat selanjutnya:

1. Diharapkan modul yang telah dirancang dapat direalisasikan dengan membuat prototype simulasi kontrol sehingga dapat mempermudah proses pembelajaran dan dapat menambah pengetahuan mengenai sistem kontrol.

2. Sebaiknya untuk dapat di kembangkan lagi modul I/O yang digunakan agar dapat lebih banyak pengetahuan dalam pemrograman dan dapat dijalankan melalui modul I/O.

3. Dalam pembuatan modul I/O alamat untuk pin masing masing input dan output harus diberikan agar memudahkan dalam proses pengkabelan (wiring).

4. Peletakan komponen dalam modul I/O membutuhkan kerapian dan kesesuaian dalam penempatan input dan output agar lebih memudahkan dalam proses pengkabelan.

Adapun dari segi Peningkatan Kompetensi adalah:

1. Diharapkan dapat Lebih dikembangkan ke teknologi industri 4.0

2. Durasi pelatihan dapat lebih lama agar materi dan praktik dapat diterima dengan baik

3. Perlunya pengembangan mata pelajaran untuk menjawab tantangan teknologi industri 4.0 


\section{Referensi}

Dian Artanto. (2012). 60 Aplikasi PLC-Mikro, PT. Elex Media Komputindo

Fathur Zaini Rachman. (2018). Mikroprosesor dan Teknik Antar Muka. Buku Ajar Politeknik Negeri Balikpapan.

Qory Hidayati, Fathur Zaini Rachman, Nur Yanti, Nurwahidah Jamal, Suhaedi, (2017). Desain Model dan Simulasi PLC-Mikrokontroler sebagai Modul Pembelajaran Berbasis PLC, JTERA - Jurnal Teknologi Rekayasa, Vol. 2, No. 2, Desember 2017.

Undang-Undang No.20 Tahun 2003 Tentang Sistem Pendidikan Nasional 